\title{
Saúde mental na Atenção Básica: identificação e organização do cuidado no estado de São Paulo
}

\author{
Mental health in Primary Care: identification and organization of \\ care in the state of São Paulo
}

Ligia Rivero Pupo', Tereza Etsuko Costa Rosa', Arnaldo Sala², Marisa Feffermann'1, Maria Cecília

Goi Porto Alves', Maria de Lima Salum e Morais'

DOI: 10.1590/0103-11042020E311

\begin{abstract}
RESUMO Este artigo teve como objetivo descrever e discutir como se identifica o sofrimento em saúde mental e como se organiza o cuidado em saúde mental nas unidades de Atenção Básica (AB) do estado de São Paulo. Para isso, baseou-se em um estudo transversal quantitativo e descritivo, realizado por meio de um inquérito telefônico em serviços de Atenção Básica à Saúde do estado. Os dados foram analisados segundo o porte do município e a presença de profissional de saúde mental na unidade. Os resultados reiteram a alta frequência com que aparecem demandas de saúde mental na $\mathrm{AB}$ e indicam: baixa proatividade na busca de demandas em saúde mental; troca de receitas e uma perspectiva mais biomédica como relevantes na identificação dos problemas; baixo planejamento do cuidado e pouca abrangência na articulação intersetorial. Também revelam a importância da presença de profissionais de saúde mental na qualificação do cuidado e no fortalecimento de ações psicossociais. As unidades do município de São Paulo se mostraram mais potentes na identificação, organização do cuidado, manejo psicossocial dos problemas e articulação intersetorial. Os municípios pequenos se destacaram pela presença de profissionais de saúde mental e pelo uso de visitas domiciliares por agentes comunitários de saúde para a identificação dos problemas.
\end{abstract}

PALAVRAS-CHAVE Saúde mental. Atenção Primária à Saúde. Necessidades e demandas de serviços de saúde. Inquérito de saúde.

1 Secretaria de Estado da Saúde, Instituto de Saúde (IS) - São Paulo (SP), Brasil.

ligiapupo@gmail.com

2 Secretaria de Estado da Saúde, Coordenadoria de Regiões de Saúde - São Paulo (SP), Brasil.
ABSTRACT This article aimed to describe and discuss how mental suffering is identified and how mental health care is organized in Primary Care services in the state of São Paulo. In order to do so, the study was based on a quantitative and descriptive cross-sectional study, carried out through a telephone survey in Primary Health Care services in the state. Data were analyzed according to the size of the city and to the presence of at least one Mental Health professional in the services. The results reiterate the high frequency with which demands for mental health appear in Primary Care services, and indicate: low proactivity in the search for problems in mental health; exchange of prescriptions and a more biomedical perspective as relevant to the identification of problems; low care planning and little coverage in intersectoral articulation. It also reveals the importance of the presence of mental health professionals in qualifying care and strengthening psychosocial actions. The services in the city of São Paulo proved to be more potent in identifying, organizing care, psychosocial management of problems, and intersectoral articulation. Small cities stood out by the presence of mental health professionals and by using home visiting by community health agents in identifying problems.

KEYWORDS Mental health. Primary Health Care. Health services needs and demand. Health survey. 


\section{Introdução}

Desde o final da década de 1970, com o movimento da Reforma Psiquiátrica Brasileira, profissionais, familiares, usuários e gestores vêm discutindo e estruturando novas formas de organizar e operar o cuidado em saúde mental, saindo de um modelo biomédico, tutelar, com exclusão social, restrição dos direitos dos indivíduos com sofrimento mental e voltando-se para um modelo de cuidado de base territorial, mais integral, horizontal, multiprofissional, intersetorial, longitudinal e contextualizado, com a construção de serviços de atenção diária organizados em rede. Essa rede de serviços substitutivos se propõe a operar na perspectiva da desinstitucionalização da pessoa com sofrimento mental, com abordagem psicossocial e comunitária, deslocando o foco da doença para o sujeito - com suas experiências, contextos, necessidades e desejos -, incluindo sua família e rede social, visando principalmente ao resgate de sua autonomia, de seus direitos individuais e sociais e à sua reinserção social1-5.

A primeira década dos anos 2000 foi de importância capital para a fundamentação e para a formalização jurídico-legal da Reforma Psiquiátrica Brasileira, da Política Nacional de Saúde Mental e do modelo de atenção psicossocial. A Lei n ${ }^{0} 10.216^{6}$, de abril de 2001 , dispôs sobre a proteção dos direitos dos indivíduos portadores de sofrimento mental, sobre a limitação à internação psiquiátrica e sobre o redirecionamento do modelo assistencial para serviços de natureza comunitária. Em fevereiro de 2002 , a Portaria $n^{0} 336^{7}$ estabeleceu as modalidades dos serviços substitutivos de atenção ambulatorial e comunitária chamados Centros de Atenção Psicossocial (Caps), definidos por ordem de porte, complexidade e abrangência populacional. Em 2003, o Programa De Volta para $\mathrm{Casa}^{8}$ gerou efeitos imediatos sobre a reinserção psicossocial de egressos de internações psiquiátricas, na medida em que garante o auxílio-reabilitação psicossocial para a atenção e o acompanhamento dessas pessoas em seu território. Em 2004, a Portaria n $2.197^{9}$ criou, no âmbito do Sistema Único de Saúde (SUS), o Programa de Atenção Integral a Usuários de Álcool e outras Drogas, incorporando a estratégia de redução de danos. Por fim, a Portaria $\mathrm{n}^{\mathbf{0}} 3.088$, de $2011^{10}$, estabeleceu as Redes de Atenção Psicossocial (Raps), com vários serviços substitutivos organizados em rede.

Apesar de essas medidas apresentarem como foco principal a desinstitucionalização dos indivíduos com transtornos mentais graves e persistentes, a pertinência e a importância da Atenção Básica (AB) no âmbito do cuidado em saúde mental nunca foram totalmente ignoradas. Em 2003, a Coordenação Geral da Saúde Mental (CGSM) do Ministério da Saúde (MS) divulgou o documento 'Saúde mental e atenção básica: o vínculo e o diálogo necessários - inclusão das ações de saúde mental na atenção básica'11, que sugeriu o apoio matricial em saúde mental para as equipes de Programa Saúde Família (PSF), propôs ações de formação em saúde mental e o acompanhamento e avaliação dessas ações da $\mathrm{AB}$, com a inclusão de ações de saúde mental no sistema de informações. Em 2005, os indicadores de saúde mental passaram a fazer parte do elenco de indicadores da $\mathrm{AB}$ inseridos no Sistema de Informações da Atenção Básica (Siab) ${ }^{\mathbf{1 2}}$. Em 2006, por meio da Portaria GM n ${ }^{0} 1.097$, de 22 de maio de $2006^{\mathbf{1 3}}$, foram incluídos parâmetros para a indicação de ações de saúde mental na $A B$ nas diretrizes para a Programação Pactuada e Integrada da Assistência à Saúde (PPI). Em 2008, a Portaria $n^{0} 154^{14}$ criou os Núcleos de Apoio à Saúde da Família (Nasf), que ampliaram o escopo e a resolutividade da rede de $\mathrm{AB}$ em relação a várias demandas, incluindo aquelas de saúde mental.

A relevância da $\mathrm{AB}$ no âmbito do cuidado em saúde mental se dá principalmente por sua proximidade com o território de vida dos usuários, por seu vínculo contínuo com a comunidade, por seu cuidado longitudinal, pela melhor gestão de doenças crônicas e condições de longa duração, por sua proximidade com diferentes recursos, organizações e dispositivos 
sociais comunitários para além do setor saúde e por ser pautada nos princípios da integralidade, interdisciplinaridade, intersetorialidade e territorialidade ${ }^{15-18}$. Sendo assim, a AB tem sido vista como estratégica para: a) o acesso inicial dos usuários ao sistema, a escuta qualificada, o acolhimento, a identificação das necessidades de saúde mental e a coordenação do cuidado; b) o desenvolvimento de ações de promoção da saúde mental, prevenção, diagnóstico e tratamento psicossocial do sofrimento mental comum; c) o acompanhamento e o desenvolvimento de ações de redução de danos de usuários de álcool e outras drogas; d) o acompanhamento longitudinal das demandas emocionais e de saúde de pacientes graves, em conjunto com Caps e urgência/emergência, para evitar internações e contribuir para a reabilitação psicossocial; d) o suporte para a redução da demanda por atendimento especializado em saúde mental15,16,18-21.

Contudo, apesar de a abordagem psicossocial de cuidado proposta por essas novas políticas considerar o indivíduo em sua multidimensionalidade e dinamismo histórico e de levar em conta os determinantes biopsíquicos e socioculturais do sofrimento mental, visando distanciar-se do foco genérico na doença, nos sintomas e na patologização da vida ${ }^{22} \mathrm{e}$, a despeito de o Ministério da Saúde propor alguns dispositivos para contribuírem para a qualificação, organização e gestão do cuidado psicossocial nas redes de atenção (acolhimento, Projeto Terapêutico Singular - PTS e Apoio Matricial) 21,23,24 a articulação e a integração da saúde mental na $\mathrm{AB}$ ainda têm-se mostrado frágil e incipiente.

Vários estudos têm apontado fatores recorrentes, que têm contribuído para a constante dificuldade de implantação e incorporação do modelo psicossocial nas unidades de saúde do SUS, incluindo a AB. Dentre os mais conhecidos, podemos citar: o modelo biomédico de sofrimento mental que se preocupa em silenciar os sintomas por meio da medicação e que ignora a dimensão subjetiva, social e existencial dos problemas ${ }^{4,25,26}$; o estereótipo de periculosidade e incapacidade relacionados com os transtornos mentais graves que geram afastamento, receio e desistência de investimento dos profissionais no cuidado para além da medicação ${ }^{\mathbf{1 , 5}}$; a falta de preparo dos profissionais, especialmente daqueles da atenção primária, sobre a temática de saúde mental4,27; a separação e a cisão do cuidado em problemas físicos e problemas emocionais/psicossociais ${ }^{17}$; o entendimento de que a saúde mental deve ser abordada apenas por especialistas $\mathbf{2 5 , 2 8 , 2 9}$; o estabelecimento de diretrizes operacionais genéricas e sem detalhamento sobre como identificar e diagnosticar, sobre quais os fluxos de atenção adequados e o tipo de abordagem terapêutica que deve ser utilizada em cada situação ${ }^{27,29}$; e a baixa articulação entre os serviços da rede pública de saúde $^{4,30}$. Tais fatores têm sido considerados determinantes significativos para as diversas dificuldades e problemas ligados tanto à forma como se identifica e se acolhe o sofrimento mental nas unidades de saúde como à forma como se organiza e se estrutura o cuidado em saúde mental na $\mathrm{AB}$.

Com relação à identificação e ao acolhimento desses problemas na rede de $\mathrm{AB}$, estudos mostram que, apesar de essas demandas serem frequentes ${ }^{31}$, os problemas de sofrimento mental se traduzem em queixas físicas, pois essas, na visão dos usuários, parecem ter mais legitimidade e escuta nas Unidades Básicas de Saúde (UBS) do que as demandas socioemocionais ${ }^{26}$. Como é sabido, a forma como se estrutura a oferta tem, entre outros fatores, influência considerável na forma como se estrutura a demanda ${ }^{32,33}$; assim, não é incomum que o sofrimento emocional e os problemas psicossociais sejam traduzidos pelos usuários em seus aspectos mais orgânicos, para que possam ter maior visibilidade ${ }^{26}$. Estudos também apontam que, em geral, não há uma escuta qualificada do sofrimento, e, sim, uma escuta de sintomas para fins de um diagnóstico de natureza mais psiquiátrica, e que as UBS são mais propensas a identificar demandas mais graves, sintomáticas, muito explícitas e 
emergenciais, e não aquelas relacionadas com a subjetividade, com o sofrimento existencial ou situacional ${ }^{26}$.

Com relação à organização das ações de cuidado em saúde mental, trabalhos indicam várias dificuldades a serem enfrentadas pela AB. Inicialmente, estudos revelam uma certa medicalização da atenção em saúde mental $28,34,35$, no sentido de que muitas experiências humanas perturbadoras e angustiantes de natureza social, conjuntural e intersubjetivas são interpretadas como de causalidade orgânica e biológica, diagnosticadas como doenças e, portanto, manejadas pelo campo da medicina por meios principalmente farmacológicos ${ }^{36-38}$. Outros trabalhos revelam ainda a prática de repetição e troca de receitas sem reavaliação das necessidades e do sofrimento envolvido em cada situação, o que pode ocorrer por pressão do paciente, por dificuldades do profissional médico em negar pedidos de receita, pelo desconforto em mudar a prescrição de outro profissional ou pelo desconhecimento de alternativas terapêuticas $\mathbf{2 8 , 3 4 , 3 9 , 4 0}$. Além dessas, algumas pesquisas encontraram como fragilidades na organização das ações em saúde mental na AB: a fragmentação do cuidado, sendo que o usuário de Caps muitas vezes não é visto como pertencente também à $\mathrm{AB}^{25}$; o baixo planejamento e a gestão insuficiente do cuidado em saúde mental nas UBS27,41; o limitado uso de ações no território, uma vez que as ações desenvolvidas o são principalmente dentro da unidade ${ }^{41}$; o reduzido uso de abordagens grupais 27; e a baixa participação dos usuários e da família no planejamento e decisão sobre as ações de cuidado ${ }^{31 .}$

Apesar de existirem diversos estudos sobre os inúmeros aspectos relativos à oferta de cuidado em saúde mental na $\mathrm{AB}$, não se dispõe hoje de informações suficientemente atualizadas e abrangentes sobre como se identifica e se organiza o cuidado em saúde mental nas unidades de AB do estado de São Paulo. Para estabelecer uma boa política de atenção em saúde mental, faz-se necessário compreender as características do sistema de prestação de cuidados atualmente existente. Para qualificar, orientar e redirecionar o cuidado em saúde mental na AB, é importante conhecer como, no momento presente, é identificado o sofrimento mental nas unidades do estado e como essas se organizam para responder aos problemas a ele referentes. Procurando responder, ao menos parcialmente, a tais questões, o presente artigo tem como objetivo descrever e discutir 'como se identifica e se organiza o cuidado em saúde mental' nas unidades de $\mathrm{AB}$ do estado de São Paulo.

\section{Material e métodos}

$\mathrm{O}$ artigo descreve e discute resultados parciais encontrados no projeto intitulado 'Inquérito sobre Tecnologias de Cuidado em Saúde Mental na Atenção Básica à Saúde no Estado de São Paulo'. Trata-se de estudo transversal quantitativo e descritivo, realizado por meio de um inquérito telefônico em serviços de Atenção Básica à Saúde de municípios do estado.

Como não foram encontradas na literatura pesquisas com a metodologia empregada e com esse porte no estado de São Paulo, o projeto buscou, de forma geral, contribuir com a apresentação de um mapeamento sobre tecnologias de cuidado em saúde mental na $\mathrm{AB}$, sobre a lógica de cuidado subjacente aos modelos de atenção e sobre práticas no cotidiano dos serviços de AB.

A população de estudo foi constituída por 4.941 estabelecimentos de saúde caracterizados como unidades de AB. Para sua identificação, utilizou-se o Cadastro Nacional de Estabelecimentos de Saúde (CNES), selecionando-se os tipos 'Posto de Saúde', 'Centro de Saúde/Unidade Básica de Saúde' ‘ 'Unidade de Saúde da Família', com base na competência abril/2017.

Para fins de cálculo do tamanho da amostra, foram considerados o porte do município e a existência de hospitais psiquiátricos na definição dos seguintes domínios de estudo: municípios com hospitais psiquiátricos (à exceção 
de São Paulo), municípios com menos de 25 mil habitantes, de 25 a 100 mil habitantes, acima de 100 mil habitantes (à exceção de São Paulo) e o município de São Paulo. Para que a amostra fosse de 100 unidades no menor domínio, foram sorteadas mil unidades no total, distribuídas em 426 municípios.

Após o sorteio, foram excluídos 45 estabelecimentos que não satisfaziam os critérios de funcionamento como unidade de $\mathrm{AB}$ ou que estavam desativados. Tendo em vista que a exclusão não interferiu nos domínios amostrais de interesse, estabeleceram-se, como amostra sorteada final, 955 unidades de $\mathrm{AB}$ localizadas no estado de São Paulo.

Antes da realização das entrevistas, houve a necessidade de proceder a algumas etapas: 1) obtenção da permissão para a realização da entrevista por parte do gestor da unidade sorteada e da autorização das respectivas Secretarias Municipais de Saúde; 2) envio do roteiro, com instruções de preenchimento, por e-mail ou correio, à escolha da unidade; 3 ) estabelecimento pela UBS da estratégia mais conveniente de preenchimento do questionário (se durante reunião de equipe, se realização de minirreuniões com os profissionais envolvidos, se indicação de um profissional responsável para buscar as informações entre os colegas etc.) - a forma de preenchimento não foi critério para considerar o questionário válido ou não; 4) marcação de hora e data com profissional indicado pelo gerente da unidade para responder ao questionário, previamente preenchido, por telefone. A entrevista telefônica consistia em transferir as respostas do questionário para um software de armazenamento das informações no banco de dados. Se os dados estivessem incompletos e/ ou considerados inadequados/inconsistentes, havia a possibilidade de reagendar novas ligações quantas vezes fossem necessárias para completar o questionário.

$\mathrm{O}$ roteiro, estruturado com respostas fechadas, foi distribuído em cinco blocos: 1) caracterização da unidade (86 questões); 2) identificação dos problemas e necessidades associados ao sofrimento mental (75 questões); 3) forma de organização do cuidado e fluxos de atenção para atender às demandas associadas à saúde e ao sofrimento mental (193 questões); 4) intervenções em saúde mental ofertadas e suas características (569 questões); e 5) articulações intersetoriais realizadas para responder às necessidades ligadas à saúde e ao sofrimento mental (70 questões). Vale destacar que o grande número de questões foi devido ao fato de que, dependendo da pergunta e da resposta, estavam previstas outras perguntas para a obtenção de informações complementares. Em grande parte das questões, a lista das opções era apresentada, sendo apenas necessário responder sim ou não. Para a realização do presente trabalho, foram selecionadas respostas a apenas algumas questões fechadas, de todos os blocos, exceto do bloco 4 . Para este artigo, foram selecionadas perguntas que pudessem trazer luz sobre a identificação e organização do cuidado em saúde mental nas UBS do estado de São Paulo. As questões analisadas estão apresentadas no quadro 1.

Quadro 1. Apresentação das questões analisadas, de acordo com os blocos selecionados

\begin{tabular}{lll}
\hline Número da Questão & Questão & Respostas \\
\hline Bloco 1 - Caracterização da unidade & \\
\hline Questão A24 & Indique os profissionais que atuam na unidade (foram in- & Médico psiquiatra \\
& dicadas 18 modalidades de profissionais e destacados para & Psicólogo \\
& análise aqueles específicos da área de saúde mental). & Terapeuta Ocupacional \\
& Assistente Social \\
\hline
\end{tabular}


Quadro 1. (cont.)

\begin{tabular}{lll}
\hline Número da Questão & Questão & Respostas \\
\hline Bloco 2 - Identificação dos problemas e necessidades associados ao sofrimento mental \\
\hline Questão B1 & Em geral, com qual frequência as demandas de saúde & 1- Diariamente \\
& mental aparecem na unidade? & 2- Semanalmente \\
& & 3- Mensalmente \\
& & 4- Bimensalmente ou menos \\
& frequentemente
\end{tabular}

Bloco 3 - Organização do cuidado e fluxos de atenção para atender as demandas associadas à saúde e ao sofrimento mental

\begin{tabular}{|c|c|c|}
\hline Questão C1 & Nesta unidade, há reuniões entre os profissionais? & $\begin{array}{l}\text { 1- } \operatorname{Sim} \\
\text { 2- Não }\end{array}$ \\
\hline Questão C2 & Essas reuniões são de que tipo? (11 opções foram listadas). & $\begin{array}{l}\text { 1- } \operatorname{Sim} \\
\text { 2- Não } \\
\text { 9- NS/NR }\end{array}$ \\
\hline Questão C5 & $\begin{array}{l}\text { Esta unidade fez algum PTS para casos de sofrimento } \\
\text { mental no último ano? }\end{array}$ & $\begin{array}{l}\text { 1- } \operatorname{Sim} \\
\text { 2- Não } \\
\text { 9- NS/NR }\end{array}$ \\
\hline Questão C8 & $\begin{array}{l}\text { Esta unidade participou de alguma atividade de matricia- } \\
\text { mento em Saúde Mental no último ano? }\end{array}$ & $\begin{array}{l}\text { 1- } \operatorname{Sim} \\
\text { 2- Não } \\
\text { 9- NS/NR }\end{array}$ \\
\hline Questão C17 & $\begin{array}{l}\text { Nos últimos três meses, para onde foram encaminhados os } \\
\text { casos de saúde mental (o entrevistado devia selecionas a } \\
\text { duas mais frequentes entre sete opções)? }\end{array}$ & \\
\hline \multicolumn{3}{|c|}{ Bloco 5 - Articulações intersetoriais para responder às necessidades ligadas à saúde e ao sofrimento menta } \\
\hline Questão E1 & $\begin{array}{l}\text { Existe articulação com grupos/instituições/organizações } \\
\text { de fora do setor saúde para promover saúde mental ou } \\
\text { cuidar do sofrimento mental? }\end{array}$ & $\begin{array}{l}\text { 1- } \operatorname{sim} \\
\text { 2- Não } \\
\text { 9- NS/NR }\end{array}$ \\
\hline Questão E2 & $\begin{array}{l}\text { Faz articulação com (foram apresentadas onze opções de } \\
\text { instituição). }\end{array}$ & $\begin{array}{l}\text { 1- } \operatorname{sim} \\
\text { 2- Não } \\
\text { 9- NS/NR }\end{array}$ \\
\hline
\end{tabular}

As entrevistas foram realizadas no período de outubro a dezembro de 2017 e de janeiro a agosto de 2018 por profissionais experientes, tendo sido gravadas mediante software próprio; e as respostas, computadas em planilhas correspondentes. Posteriormente, os dados foram transcritos para planilhas Excel ${ }^{\circledR}$ e, finalmente, para planilhas do software SPSS.

Neste estudo, estão apresentados dados absolutos e percentuais e suas possíveis associações testadas estaticamente por meio de testes de chi-quadrado, calculados com a aplicação do software SPSS Statistics 20. Como categorias de análise, foram considerados: a) 
o porte do município, em função da possível complexidade das unidades presentes no território; e b) a existência de profissional de saúde mental (psicólogo(a), psiquiatra, terapeuta ocupacional e/ou assistente social), pelo fato de sua presença poder influenciar nos resultados.

O projeto foi inserido na plataforma Brasil e submetido à aprovação do Comitê de Ética em Pesquisa do Instituto de Saúde (Cepis) da Secretaria de Estado de São Paulo e, quando necessário, submetido também a outros Comitês de Ética em Pesquisa ou órgãos análogos nos municípios estudados. Antes de iniciar a entrevista, era gravado o consentimento do entrevistado, mediante Termo de Consentimento Livre e Esclarecido (TCLE) previamente elaborado e lido pelo(a) entrevistador(a). Obedeceuse, na execução do projeto, ao disposto pela Resolução $n^{\circ} 466 / 12$; sendo aprovado pelo parecer $n^{\circ}$ 2.018.261 do Cepis.

\section{Resultados e discussão}

Ao final da coleta de dados, obteve-se um total de 879 unidades que responderam satisfatoriamente ao questionário deste estudo, considerando-se uma perda de cerca de $8 \%$ de unidades que acabaram não participando da pesquisa. A não resposta foi relacionada com os seguintes motivos: não autorização do gestor municipal; dados incompletos de endereços das unidades; dificuldades em contatar as pessoas que poderiam autorizar a entrevista ou em estabelecer contato com o(s) profissional (is) indicado (s) para respondê-la.

A principal limitação do presente artigo está relacionada com a metodologia, pois o questionário previa que as informações deveriam ser respondidas em conjunto pela equipe de trabalhadores da unidade, mas, a despeito dessa instrução, não foi possível ter certeza se o instrumento foi respondido por um profissional somente ou pela equipe, ou em parte. Esse obstáculo ocorreu, visto que, durante a coleta telefônica, não foi questionada a forma de preenchimento do instrumento (se isoladamente ou em equipe e por quais profissionais). Observou-se, a posteriori, que algumas questões do instrumento, por terem sido previamente estabelecidas após apenas uma pequena fase de pré-teste, não forneceram todas as informações buscadas pelos objetivos do estudo.

No entanto, como pontos fortes desta pesquisa, pode-se ressaltar sua abrangência, a obtenção de um elevado número de respostas (92\% das unidades), apesar de ter havido grande empenho em conseguir realizar as entrevistas. Esse número foi resultado da persistência dos pesquisadores na busca de contato com as unidades sorteadas e na insistência na obtenção das respostas, por meio de várias ligações telefônicas e mensagens eletrônicas (em média, houve 14 tentativas para conseguir concluir uma entrevista).

\section{Caracterização das unidades}

Das 879 UBS compreendidas no estudo, 24,7\% pertenciam a municípios com população de até 25 mil habitantes (municípios pequenos); $26,6 \%$, a municípios com população entre 25 mil e 100 mil habitantes (municípios médios); $38,1 \%$, a municípios com população acima de 100 mil habitantes (municípios grandes - excetuando o município de São Paulo); e 10,6\% das unidades pertenciam ao município de São Paulo (tabela1). 
Tabela 1. Distribuição das Unidades Básicas de Saúde por presença de profissional de saúde mental, segundo o porte populacional dos municípios onde as unidades estão localizadas*

\begin{tabular}{|c|c|c|c|c|c|c|}
\hline \multirow{2}{*}{\multicolumn{2}{|c|}{$\begin{array}{l}\text { Presença de profissional } \\
\text { de Saúde Mental }\end{array}$}} & \multicolumn{4}{|c|}{ Porte populacional do município } & \multirow[t]{2}{*}{ Total } \\
\hline & & Até 25 mil hab. & De 25 a 100 mil hab. & 100 mil hab. e mais & São Paulo & \\
\hline \multirow[t]{2}{*}{ Não } & N & 107 & 160 & 199 & 26 & 492 \\
\hline & $\%$ no porte & $49,80 \%$ & $69,00 \%$ & $59,80 \%$ & $28,30 \%$ & $56,40 \%$ \\
\hline \multirow[t]{2}{*}{ Sim } & N & 108 & 72 & 134 & 66 & 380 \\
\hline & $\%$ no porte & $50,20 \%$ & $31,00 \%$ & $40,20 \%$ & $71,70 \%$ & $43,60 \%$ \\
\hline \multirow[t]{2}{*}{ Total } & N & 215 & 232 & 333 & 92 & 872 \\
\hline & $\%$ no porte & $100,00 \%$ & $100,00 \%$ & $100,00 \%$ & $100,00 \%$ & $100,00 \%$ \\
\hline
\end{tabular}

${ }^{*}$ valor de $p=0,000$ (chi quadrado de Pearson).

Em relação ao tipo de UBS, 32,6\% correspondiam a Unidades Básicas Tradicionais; 47,1\%, a Unidades de Saúde da Família; e 20,3\%, a Unidades Mistas (equipes de saúde da família e equipes tradicionais no mesmo serviço) (dados não apresentados em tabela). A configuração da amostra foi bastante representativa do estado de São Paulo, já que a presença de UBS com equipe de saúde da família (exclusivamente ou em unidades tradicionais) tende a ser mais frequente nos municípios menores e menos frequente entre os municípios grandes e no município de São Paulo (dados não expostos em tabela). O fenômeno da maior presença de equipes de saúde da família em municípios pequenos explica-se pelo processo de implantação dessas equipes, em que os municípios de menor porte populacional obtiveram progressivamente maiores coberturas de população em relação aos de porte intermediário e aos de grande porte, no período entre 1998 e 2006, conforme apontado em publicação do Ministério da Saúde ${ }^{\mathbf{4 2}}$. Para o período mais recente, é possível verificar a manutenção dessa maior cobertura entre os municípios pequenos, a partir dos dados de cobertura da $\mathrm{AB}$ disponíveis no site e-Gestor Atenção Básica, acessível no endereço: https:// egestorab.saude.gov.br/paginas/acessoPublico/relatorios/relHistoricoCoberturaAB.xhtml.

Do conjunto das UBS incluídas no estudo, somente $43,5 \%$ possuíam pelo menos um profissional relacionado com o cuidado em saúde mental (psiquiatra, psicólogo, terapeuta ocupacional ou assistente social) (tabela 1). A relativamente pequena presença de profissionais de saúde mental nas unidades de $\mathrm{AB}$ do estado de São Paulo está provavelmente relacionada com as características intrínsecas da própria Reforma Psiquiátrica Brasileira, da Política Nacional de Saúde Mental ${ }^{6}$ e do formato proposto para a Raps ${ }^{7}$, que não privilegiaram a presença desses profissionais em UBS.

A necessidade premente de acabar com os abusos, a situação de exclusão social e o desrespeito aos direitos dos indivíduos com sofrimento mental internados em hospitais psiquiátricos fizeram com que o foco principal da Política Nacional de Saúde Mental fosse a rápida desinstitucionalização, bem como a implementação de serviços substitutivos e de urgência/emergência. Para aumentar a resolubilidade e a integralidade no cuidado em saúde mental na $\mathrm{AB}$, a estratégia escolhida pela Reforma Psiquiátrica brasileira foi a de um cuidado colaborativo, pautado na troca de saberes e na construção compartilhada entre equipes de saúde mental e profissionais de atenção primária, denominado apoio matricial21,23; e, portanto, não houve um investimento na presença física de profissionais de saúde mental nas unidades da rede básica de saúde. Tal proposta previu um suporte técnico-pedagógico às equipes de $A B$ feito 
por profissionais de saúde mental alocados em Caps e, posteriormente, também em Nasf $f^{\mathbf{1 8} 23}$. Além disso, a ideia de trabalho em rede incentivou que as equipes de $\mathrm{AB}$ trabalhassem em conjunto com as equipes da atenção especializada no cuidado em saúde mental ${ }^{\mathbf{4 3}}$; e o processo de construção da Raps, focado no financiamento dos Caps, realocou parte importante dos profissionais de saúde mental dos municípios para esses serviços especializados. Embora se reconheça que houve um grande passo na direção da desinstitucionalização das pessoas com transtornos mentais severos, não há evidências de que essa estratégia tenha sido a melhor em termos de resolubilidade e efetividade no cuidado de pessoas com sofrimento mental comum, de menor gravidade e mais prevalentes ${ }^{25,26}$.

Analisando a distribuição da presença de profissional de saúde mental nas unidades segundo o porte populacional dos municípios, as diferenças são significativas, sendo que $72,0 \%$ das unidades no município de São Paulo possuíam profissional de saúde mental, seguidas pelas unidades nos municípios pequenos $(49,8 \%)$, pelos grandes $(40,0 \%)$ e médios $(31,2 \%)$ (tabela 1). A maior frequência de profissionais de saúde mental no município de São Paulo pode ser devida às ações de saúde mental propostas por gestões anteriores do final da década de 1980 até início dos anos $2000^{22}$. Nesse período, privilegiaram-se políticas de incentivo à alocação de profissionais de saúde mental nas UBS de maior porte sob a gestão do município de São Paulo, assim como aquelas sob gestão estadual, que foram municipalizadas algum tempo depois.

As equipes das unidades tradicionais, bastante presentes no município de São Paulo (58,7\%), contaram com menos Apoio Matricial, pois esse foi desenhado principalmente para o suporte às equipes da Estratégia Saúde da
Família (ESF), sendo que 39,7\% das UBS do município de São Paulo responderam não contar com equipes de Nasf (dados não apresentados em tabela). Por esse motivo, também, é possível que as unidades tradicionais tenham continuado mantendo profissionais de saúde mental em suas equipes. Em contraponto, a maior presença de profissionais de saúde mental, sobretudo de psicólogos (dados não apresentados em tabela) em municípios de pequeno porte (até $25 \mathrm{mil} \mathrm{hab.),} \mathrm{provavelmente}$ deve-se à escassa presença de equipamentos de atenção especializada nesses municípios ambulatórios de saúde mental (19,9\%), Caps I (19\%) e Caps II (2\%) -, o que pode ter tornado necessária a contratação/manutenção de profissional de saúde mental em unidades de $\mathrm{AB}^{17}$.

\section{Identificação dos problemas e demandas associados ao sofrimento mental}

No geral, 50,7\% das unidades responderam que identificavam diariamente demandas associadas ao sofrimento mental (tabela 2); e essas, somadas àquelas que responderam identificar semanalmente esse tipo de demanda, chegam a $80 \%$ de unidades. Tal dado reforça a importância da atenção primária como espaço estratégico e oportuno para identificação, acesso, cuidado e acompanhamento longitudinal dessas demandas. Entretanto, a frequência com que foram identificadas as demandas de saúde mental muda de acordo com o porte populacional do município em que se localiza a UBS. Quanto menor o porte do município, menor foi a frequência de resposta afirmativa a essa questão. Das unidades do município de São Paulo, 79,6\% identificaram tais demandas diariamente, e isso ocorreu em apenas $38,2 \%$ nas unidades dos municípios pequenos. 
Tabela 2. Percentuais de respostas afirmativas às questões relativas ao processo de identificação das demandas relacionadas com o sofrimento mental, segundo o porte populacional dos municípios onde as unidades estão localizadas, e segundo a presença de profissional de saúde mental na unidade

\begin{tabular}{|c|c|c|c|c|c|c|c|c|c|c|c|c|}
\hline \multirow[t]{2}{*}{ Tema } & \multirow[t]{2}{*}{ Questão } & \multicolumn{4}{|c|}{ Porte populacional do município } & \multirow[t]{2}{*}{$\%$ total } & \multicolumn{2}{|c|}{$\mathrm{N}$ total valor de } & \multicolumn{2}{|c|}{ Profissional de SM } & \multicolumn{2}{|c|}{ total valor de } \\
\hline & & $\begin{array}{r}\text { Até } 25 \text { mil } \\
\text { hab. }\end{array}$ & $\begin{array}{l}25 \text { a } 100 \\
\text { mil hab. }\end{array}$ & $\begin{array}{l}100 \text { mil } \\
\text { hab. e + }\end{array}$ & $\begin{array}{r}\text { São } \\
\text { Paulo }\end{array}$ & & "sim" & $p^{\star}$ & Não & Sim & & $p^{*}$ \\
\hline 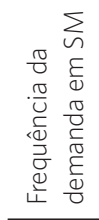 & Demanda diária de SM? & $38,2 \%$ & $43,6 \%$ & $55,8 \%$ & $79,6 \%$ & $50,7 \%$ & 446 & 0,000 & $43,5 \%$ & $59,9 \%$ & $50,6 \%$ & 0,000 \\
\hline \multirow{9}{*}{ 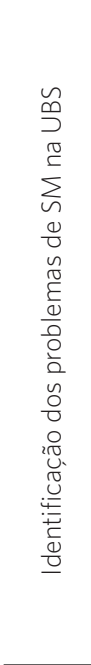 } & $\begin{array}{l}\text { Encaminhamento c/ Diag- } \\
\text { nóstico }\end{array}$ & $31,3 \%$ & $25,6 \%$ & $30,1 \%$ & $31,2 \%$ & $29,4 \%$ & 258 & 0,528 & $26,5 \%$ & $33,0 \%$ & $29,3 \%$ & 0,035 \\
\hline & $\begin{array}{l}\text { Encaminhamento s/ Diag- } \\
\text { nostico }\end{array}$ & $21,2 \%$ & $17,5 \%$ & $21,8 \%$ & $31,2 \%$ & $21,5 \%$ & 189 & 0,060 & $14,6 \%$ & $30,4 \%$ & $21,5 \%$ & 0,000 \\
\hline & Pedido de troca de receita & $64,5 \%$ & $70,9 \%$ & $77,3 \%$ & $58,1 \%$ & $70,4 \%$ & 619 & 0,000 & $76,2 \%$ & $62,8 \%$ & $70,4 \%$ & 0,000 \\
\hline & $\begin{array}{l}\text { Demanda especifica do } \\
\text { usuário }\end{array}$ & $43,8 \%$ & $42,7 \%$ & $47,2 \%$ & $52,7 \%$ & $45,7 \%$ & 402 & 0,352 & $42,7 \%$ & $49,7 \%$ & $45,7 \%$ & 0,037 \\
\hline & $\begin{array}{l}\text { Demanda específica do } \\
\text { acompanhante }\end{array}$ & $42,4 \%$ & $47,4 \%$ & $40,0 \%$ & $44,1 \%$ & $43,0 \%$ & 378 & 0,364 & $42,3 \%$ & $44,0 \%$ & $43,0 \%$ & 0,615 \\
\hline & $\begin{array}{l}\text { Pelo comportamento do } \\
\text { usuário }\end{array}$ & $24,9 \%$ & $23,1 \%$ & $21,8 \%$ & $19,4 \%$ & $22,6 \%$ & 199 & 0,715 & $22,8 \%$ & $22,3 \%$ & $22,6 \%$ & 0,834 \\
\hline & Usuário em crise & $18,9 \%$ & $12,8 \%$ & $7,5 \%$ & $15,1 \%$ & $12,5 \%$ & 110 & 0,001 & $11,8 \%$ & $13,4 \%$ & $12,5 \%$ & 0,497 \\
\hline & $\begin{array}{l}\text { No atendimento de outras } \\
\text { demandas }\end{array}$ & $10,6 \%$ & $19,2 \%$ & $23,3 \%$ & $25,8 \%$ & $19,3 \%$ & 170 & 0,001 & $16,8 \%$ & $22,8 \%$ & $19,4 \%$ & 0,027 \\
\hline & Na visita domiciliar & $19,4 \%$ & $13,2 \%$ & $11,9 \%$ & $15,1 \%$ & $14,4 \%$ & 127 & 0,101 & $16,8 \%$ & $11,3 \%$ & $14,4 \%$ & 0,020 \\
\hline \multirow{13}{*}{ 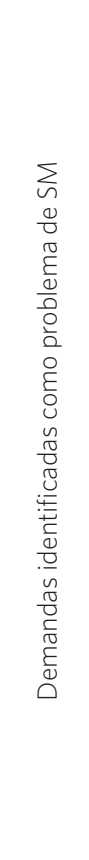 } & $\begin{array}{l}\text { Queixas escolares ou pré- } \\
\text {-escolares }\end{array}$ & $55,3 \%$ & $52,6 \%$ & $66,1 \%$ & $70,5 \%$ & $60,3 \%$ & 517 & 0,001 & $56,2 \%$ & $65,5 \%$ & $60,2 \%$ & 0,006 \\
\hline & Conflito familiar/casal & $54,8 \%$ & $60,6 \%$ & $72,7 \%$ & $78,0 \%$ & $65,6 \%$ & 563 & 0,000 & $62,8 \%$ & $69,3 \%$ & $65,6 \%$ & 0,047 \\
\hline & Queixas Comportamentais & $78,4 \%$ & $77,8 \%$ & $85,6 \%$ & $90,0 \%$ & $82,2 \%$ & 702 & 0,010 & $79,2 \%$ & $86,0 \%$ & $82,1 \%$ & 0,010 \\
\hline & Álcool e outras drogas & $90,7 \%$ & $89,3 \%$ & $95,5 \%$ & $100,0 \%$ & $93,1 \%$ & 813 & 0,001 & $90,5 \%$ & $96,6 \%$ & $93,1 \%$ & 0,000 \\
\hline & $\begin{array}{l}\text { Perdas e situações traumá- } \\
\text { ticas }\end{array}$ & $78,0 \%$ & $78,4 \%$ & $83,3 \%$ & $93,4 \%$ & $81,8 \%$ & 705 & 0,006 & $77,6 \%$ & $87,0 \%$ & $81,7 \%$ & 0,000 \\
\hline & Depressão/ Ansiedade & $98,6 \%$ & $96,6 \%$ & $97,9 \%$ & $98,9 \%$ & $97,8 \%$ & 857 & 0,406 & $97,4 \%$ & $98,4 \%$ & $97,8 \%$ & 0,298 \\
\hline & Situações de violência & $61,4 \%$ & $58,3 \%$ & $75,1 \%$ & $94,6 \%$ & $69,4 \%$ & 594 & 0,000 & $64,3 \%$ & $76,3 \%$ & $69,5 \%$ & 0,000 \\
\hline & Psicose/ Surto/Mania & $86,9 \%$ & $77,1 \%$ & $85,5 \%$ & $93,5 \%$ & $84,4 \%$ & 731 & 0,001 & $79,4 \%$ & $90,7 \%$ & $84,3 \%$ & 0,000 \\
\hline & $\begin{array}{l}\text { Problemas decorrentes do } \\
\text { Trabalho }\end{array}$ & $62,5 \%$ & $55,9 \%$ & $66,2 \%$ & $83,3 \%$ & $64,3 \%$ & 550 & 0,000 & $58,1 \%$ & $72,1 \%$ & $64,2 \%$ & 0,000 \\
\hline & Somatizações/poli queixas & $78,0 \%$ & $77,3 \%$ & $82,3 \%$ & $94,5 \%$ & $81,2 \%$ & 700 & 0,002 & $79,3 \%$ & $83,3 \%$ & $81,0 \%$ & 0,131 \\
\hline & $\begin{array}{l}\text { Busca por receita de psico- } \\
\text { fármaco }\end{array}$ & $92,1 \%$ & $94,9 \%$ & $95,5 \%$ & $97,8 \%$ & $94,7 \%$ & 829 & 0,164 & $95,4 \%$ & $93,9 \%$ & $94,8 \%$ & 0,348 \\
\hline & $\begin{array}{l}\text { Sofrimento emocional ines- } \\
\text { pecífico }\end{array}$ & $79,3 \%$ & $74,1 \%$ & $84,4 \%$ & $94,6 \%$ & $81,5 \%$ & 703 & 0,000 & $76,8 \%$ & $87,7 \%$ & $81,5 \%$ & 0,000 \\
\hline & $\begin{array}{l}\text { Transtorno do desenvolvi- } \\
\text { mento }\end{array}$ & $62,6 \%$ & $54,3 \%$ & $74,2 \%$ & $90,8 \%$ & $67,8 \%$ & 562 & 0,000 & $61,4 \%$ & $75,7 \%$ & $67,6 \%$ & 0,000 \\
\hline
\end{tabular}


Tabela 2. (cont.)

\begin{tabular}{|c|c|c|c|c|c|c|c|c|c|c|c|c|}
\hline \multirow[t]{2}{*}{ Tema } & \multirow[t]{2}{*}{ Questão } & \multicolumn{4}{|c|}{ Porte populacional do município } & \multirow[t]{2}{*}{$\%$ total } & \multicolumn{2}{|c|}{$\mathrm{N}$ total valor de } & \multicolumn{2}{|c|}{ Profissional de SM } & \multicolumn{2}{|c|}{ total valor de } \\
\hline & & $\begin{array}{r}\text { Até } 25 \text { mil } \\
\text { hab. }\end{array}$ & $\begin{array}{c}25 \text { a } 100 \\
\text { mil hab. }\end{array}$ & $\begin{array}{l}100 \text { mil } \\
\text { hab. e + }\end{array}$ & $\begin{array}{r}\text { São } \\
\text { Paulo }\end{array}$ & & "sim" & $p^{\star}$ & Não & Sim & & $p^{\star}$ \\
\hline \multirow{9}{*}{ 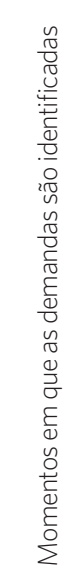 } & $\begin{array}{l}\text { Recepção/Triagem/ Aco- } \\
\text { Ihimento }\end{array}$ & $82,7 \%$ & $91,5 \%$ & $93,0 \%$ & $89,0 \%$ & $89,6 \%$ & 779 & 0,001 & $90,1 \%$ & $89,2 \%$ & $89,7 \%$ & 0,663 \\
\hline & Sala de Espera & $38,3 \%$ & $34,6 \%$ & $42,5 \%$ & $42,2 \%$ & $39,3 \%$ & 333 & 0,278 & $38,8 \%$ & $39,9 \%$ & $39,3 \%$ & 0,753 \\
\hline & Atendimento Médico & $99,1 \%$ & $99,1 \%$ & $98,8 \%$ & $100,0 \%$ & $99,1 \%$ & 867 & 0,760 & $99,4 \%$ & $98,7 \%$ & $99,1 \%$ & 0,275 \\
\hline & $\begin{array}{l}\text { Atendimento de Enferma- } \\
\text { gem }\end{array}$ & $96,3 \%$ & $95,3 \%$ & $97,6 \%$ & $98,9 \%$ & $96,8 \%$ & 843 & 0,273 & $97,0 \%$ & $96,6 \%$ & $96,8 \%$ & 0,744 \\
\hline & $\begin{array}{l}\text { Atendimento em Odonto- } \\
\text { logia }\end{array}$ & $29,6 \%$ & $37,7 \%$ & $53,4 \%$ & $56,2 \%$ & $43,6 \%$ & 360 & 0,000 & $39,5 \%$ & $49,0 \%$ & $43,6 \%$ & 0,006 \\
\hline & $\begin{array}{l}\text { Atendimento de outros pro- } \\
\text { fissionais de nível superior }\end{array}$ & $70,5 \%$ & $54,4 \%$ & $66,4 \%$ & $94,6 \%$ & $67,3 \%$ & 576 & 0,000 & $44,1 \%$ & $96,3 \%$ & $67,1 \%$ & 0,000 \\
\hline & Atividades de grupo & $33,0 \%$ & $38,9 \%$ & $55,2 \%$ & $80,4 \%$ & $48,2 \%$ & 411 & 0,000 & $43,0 \%$ & $54,5 \%$ & $48,1 \%$ & 0,001 \\
\hline & Atendimento Domiciliar & $81,2 \%$ & $73,6 \%$ & $70,6 \%$ & $90,2 \%$ & $76,1 \%$ & 657 & 0,000 & $73,7 \%$ & $79,2 \%$ & $76,1 \%$ & 0,059 \\
\hline & Visita Domiciliar do ACS & $82,7 \%$ & $70,0 \%$ & $67,2 \%$ & $61,5 \%$ & $71,1 \%$ & 619 & 0,000 & $73,1 \%$ & $68,3 \%$ & $71,0 \%$ & 0,120 \\
\hline
\end{tabular}

* valor de p para chi quadrado de Pearson.

A elevação no percentual de unidades que identificaram diariamente demandas em saúde mental também esteve associada com a presença de profissional de saúde mental. Contudo, é interessante notar que, como referido anteriormente, nos municípios de pequeno porte, menos unidades declararam identificação diária desse tipo de demanda, apesar de possuírem em quase $50 \%$ das unidades entrevistadas algum profissional de saúde mental. Ao longo do artigo, discutiremos a influência da presença de profissional de saúde mental nas unidades sob diversos aspectos.

Esses resultados corroboram inúmeros estudos que indicam que tanto a população traz regularmente o sofrimento mental como demanda para os serviços de AB quanto os profissionais da atenção primária conseguem perceber esses problemas e demandas com certa frequência 17,26,27,29,31. No entanto, diversos são os desafios desde o reconhecimento do problema de saúde mental até o manejo adequado dele. A própria identificação da problemática de saúde mental varia de acordo com características organizacionais da unidade que favorecem ou não essa identificação (carga de trabalho, tempo de atendimento, planejamento prévio de ofertas de cuidado para esses problemas), de acordo com o preparo dos profissionais para identificação dessas demandas e seu acolhimento e de acordo com o tipo de profissional presente na unidade, especializado ou não 21,26,35,44.

Ressalte-se que a maior parte das unidades $(70,4 \%)$ teve o pedido por troca de receitas como a principal forma de identificação de problemas de saúde mental (tabela 2). Tal fato pode indicar: 1) foco acentuado na medicação; 2) favorecimento dessa forma de tratamento por ser mais imediata, bem como falta de preparo ou de tempo dos profissionais para adotar formas alternativas de cuidado; 3 ) maior identificação de casos já existentes e em tratamento, assim como tendência a seguir procedimentos preexistentes no histórico dos usuários. Tal situação tem sido apontada e discutida em vários estudos nacionais que se preocupam com a medicalização da atenção à saúde mental na atenção primária. Vale lembrar que a simples troca de receita significa que a preocupação é somente com o controle dos sintomas, em contraposição a uma avaliação 
e investigação de natureza psicossocial que leva em consideração os fatores contextuais, interpessoais e emocionais desencadeantes do sofrimento mental4,17,25,28,29,35. A alta frequência de troca de receitas pode evidenciar, também, a alta demanda por psicotrópicos feita pelos próprios usuários condicionados ao uso desses medicamentos ${ }^{4}$, a existência de poucas ações para diminuir o uso abusivo de psicotrópicos na unidade $\mathrm{e}^{27} \mathrm{e}$, ainda, a visão biomédica e fragmentada do cuidado, que persiste a despeito da existência de profissionais de saúde mental não médicos nos serviços.

As outras duas formas de identificação relatadas por um número expressivo de unidades, ainda estão abaixo dos $50 \%$ e foram: por demanda específica do usuário (45,7\%) e por demanda do acompanhante (43,0\%). Essas três formas de identificação mais apontadas sugerem, ainda, certa passividade das unidades na busca ativa por situações e experiências de sofrimento mental no território, visto que os atendimentos em saúde mental dependem, de forma expressiva, do pedido explícito do usuário ou de seu familiar/acompanhante. A falta de busca ativa e de rastreamento intencional de pessoas em sofrimento mental no território e na unidade favorece o fato de que apenas demandas explícitas, sintomáticas, emergenciais ou graves sejam preferencialmente identificadas na $\mathrm{AB}^{\mathbf{4}, 26}$.

As demandas que foram reconhecidas por um maior número de unidades como problemas de sofrimento mental, em consonância com outros estudos nacionais e internacionais, foram a ansiedade e a depressão $(97,8 \%)^{21,45,46}$, seguidas pela busca por receita de psicofármacos/psicotrópicos (94,7\%) e uso de álcool e outras drogas $(93,1 \%)^{47}$. Como se pode observar, praticamente todas as unidades responderam que identificavam tais problemáticas, independentemente do porte populacional do município em que estavam localizadas (tabela 2), o que indica que o tamanho do município no qual a unidade está localizada não influencia, pelo menos, no reconhecimento desses problemas na $\mathrm{AB}$.
Chama a atenção o fato de que as queixas decorrentes de problemas no trabalho, queixas escolares e familiares e transtornos do desenvolvimento terem sido identificadas em apenas dois terços das unidades como demandas de saúde mental (tabela 2). Esse dado pode indicar, por parte dos profissionais dos serviços, baixa percepção, interesse e rastreamento intencional do sofrimento existencial e subjetivo que se manifesta em dificuldades e angústias vividas nas várias esferas da vida cotidiana. Tais angústias, muitas vezes, estão ligadas ao contexto psicossocial dos usuários e não se apresentam necessariamente na forma de sintomas e quadros clássicos de depressão e ansiedade $\mathbf{5 , 4 1 , 4 4}$. Com exceção das demandas mais prevalentes, a presença de profissionais de saúde mental na unidade contribui significativamente para a identificação de vários problemas de saúde mental. No entanto, vale lembrar que a mera disponibilidade de profissionais de saúde mental não garante a identificação qualificada de problemas e um bom cuidado nessa área. A organização do processo de trabalho e do envolvimento da equipe, ou seja, de um trabalho efetivamente multiprofissional, depende de outras varáveis além da presença de profissional de saúde mental ${ }^{5}$.

Os principais momentos de atenção na unidade em que são identificados os problemas de sofrimento mental são as consultas médicas e de enfermagem com $99,1 \%$ e $96,8 \%$ de frequência respectivamente (tabela 2). Esses momentos se mostraram mais relevantes para a identificação desses problemas, independentemente do porte do município e da presença de profissional de saúde mental. A consulta médica e de enfermagem são espaços já legitimados pela população para exposição sobre os sintomas relacionados com a saúde (pedidos de ajuda, troca de receitas). A recepção/triagem/acolhimento também se mostrou um espaço relevante na identificação de problemas de saúde mental, tendo sido a resposta de $89,6 \%$ das unidades.

Dados da literatura indicam que os espaços de atendimento em grupo estão normalmente 
associados aos cuidados em saúde mental27,29. Ao mesmo tempo, os grupos de várias naturezas realizados nas unidades podem ser também momentos estratégicos para a identificação de problemas e demandas associados ao sofrimento mental. Neste estudo, contudo, os espaços de grupo foram percebidos como momentos estratégicos para a identificação dos problemas de saúde mental somente por $33 \%$ das unidades (que citaram identificação de demandas nas atividades de grupo de todas as naturezas) e por $38,3 \%$ (que mencionaram identificação de demandas na sala de espera). É possível que a realização de grupos esteja relacionada com unidades mais bem estruturadas fisicamente e, também, à presença de profissionais disponíveis para tais atividades. Essa suposição pode ser confirmada pelo fato de que as atividades de grupo e o atendimento domiciliar foram citados como momentos mais frequentes para a identificação do sofrimento mental entre as unidades do município de São Paulo do que naquelas situadas nos demais municípios.

Muitos autores têm discutido a importância e o papel estratégico das visitas domiciliares na identificação e no cuidado em saúde mental ${ }^{31,41}$. Apesar de menos de $20 \%$ das unidades relatarem como forma de identificação do sofrimento mental a visita domiciliar, quando se perguntou em que momentos do atendimento as demandas de saúde mental eram identificadas, a visita domiciliar realizada pelos Agentes Comunitários de Saúde (ACS) foi relatada como um momento significativamente utilizado na identificação, especialmente em municípios pequenos (82,7\%) (tabela 2). Os ACS têm sido percebidos cada vez mais como figuras estratégicas e essenciais na identificação e no cuidado do sofrimento mental, pois têm a oportunidade de se vincular às famílias e conhecer suas necessidades psicossociais para além dos sintomas e doenças ${ }^{5,31,41,48}$. Cabe lembrar que $67,4 \%$ da amostra deste estudo foi composta por unidades com equipes de saúde da família (ESF ou mistas) que deveriam realizar regularmente visitas domiciliares.

\section{Organização do cuidado e fluxo de atenção}

A atenção psicossocial em saúde mental implica um trabalho de gestão do cuidado utilizando-se recursos de dentro e de fora das unidades, envolvendo discussão e planejamento do cuidado em equipe e em corresponsabilização com o usuário. O PTS pode contribuir para que tal cuidado seja mais singularizado, contextualizado e menos centrado em diagnóstico, sintomas e doença ${ }^{49-51}$.

Em relação a ações para organização do cuidado em saúde nas unidades entrevistadas, $85,3 \%$ declararam realizar reuniões periódicas entre os profissionais. No entanto, no que tange aos cuidados com pessoas em sofrimento mental, a porcentagem de unidades que realizavam com regularidade reuniões para organização das ações de cuidado em saúde mental diminuiu consideravelmente: apenas $48,7 \%$ faziam reuniões para a formulação de PTS em saúde mental e $55,9 \%$ realizavam reuniões para discussão de casos de saúde mental (tabela 3). O resultado mais surpreendente foi que o percentual caiu para $31,3 \%$ quando a pergunta se referiu a ter, efetivamente, realizado gestão de caso de sofrimento mental por meio de PTS no último ano. Esse percentual é menor ainda nos municípios de pequeno porte $(18,2 \%)$ e vai aumentando conforme aumenta o tamanho do município, chegando a $73,3 \%$ entre as unidades no município de São Paulo. Situação bastante semelhante foi observada em relação à participação em atividades de matriciamento em saúde mental no último ano, com percentuais significativamente maiores em municípios grandes e no município de São Paulo. Tal dado pode estar relacionado com uma maior organização da rede de atenção em saúde mental nessas localidades e com uma maior organização estrutural das próprias unidades nos municípios maiores, bem como referente à presença de Nasf. Vale lembrar que a presença de Nasf relatada pelas unidades básicas do estudo é de $43,9 \%$, a qual aumenta com 
o tamanho do município - sendo que, nos municípios menores, há somente $36,8 \%$ de equipes de Nasf; nos municípios acima de
100 mil habitantes, 45,5\%; e no município de São Paulo, 61,3\% - dados não apresentados em tabela.

Tabela 3. Percentuais de respostas afirmativas às questões relativas à forma de organização do cuidado e fluxos de atenção para atender às demandas em saúde mental, segundo o porte populacional dos municípios onde as unidades estão localizadas, e segundo a presença de profissional de saúde mental na unidade

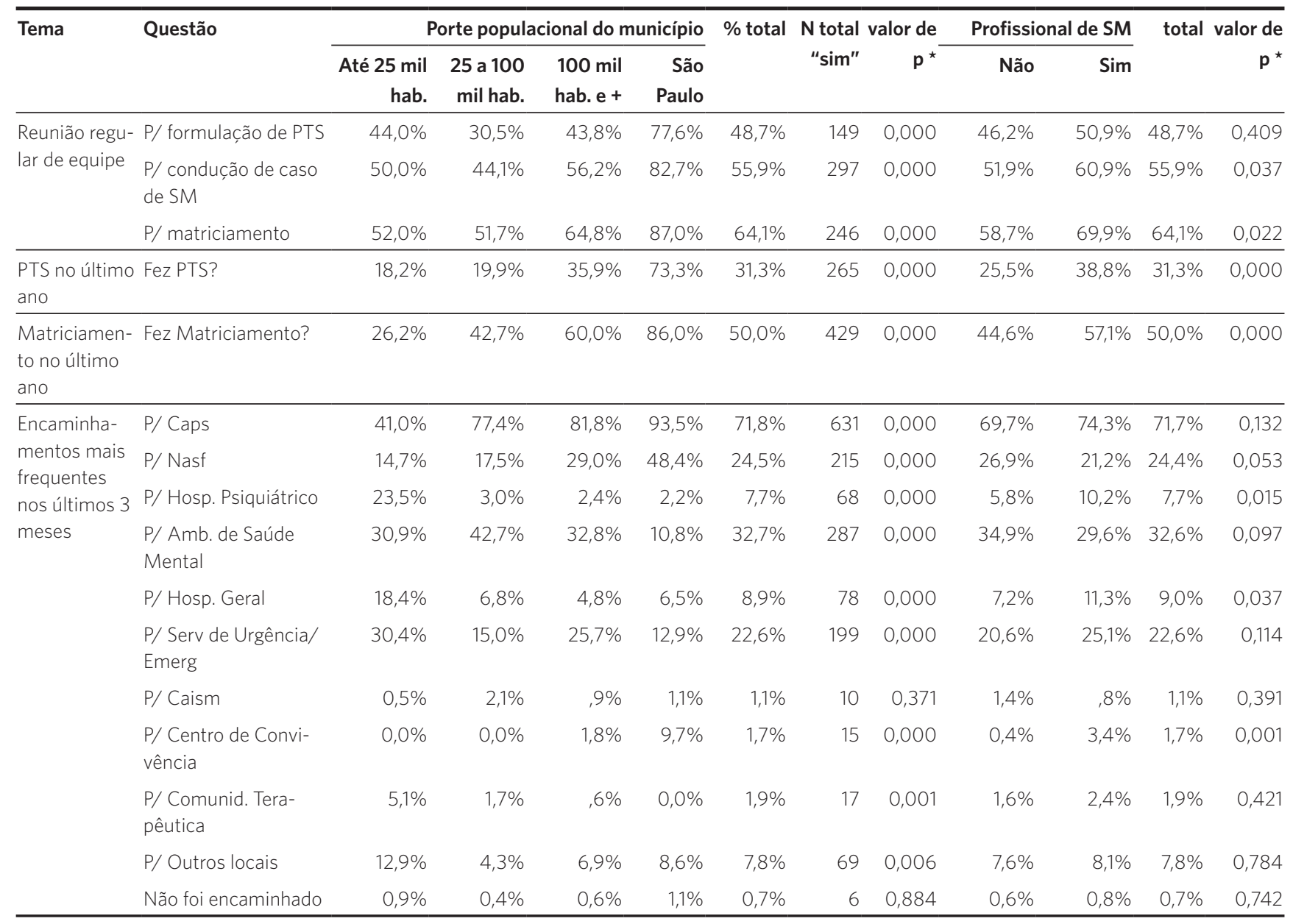

* valor de p para chi quadrado de Pearson.

A presença de algum profissional de saúde mental na unidade (assistente, social, psicólogo, terapeuta ocupacional e/ou psiquiatra) está relacionada com um aumento de reuniões para execução de PTS, condução de casos de saúde mental e matriciamento, sendo que as unidades com esses profissionais também realizaram mais ações de PTS e de matriciamento no último ano (tabela 3). Esse dado pode indicar maior foco em questões de saúde mental devido à formação acadêmica, mas também sugere que a presença de um profissional da área favorece a gestão de casos em equipe, ou seja, mostra também que tais profissionais podem contribuir para o fomento do trabalho interdisciplinar em saúde mental.

$\mathrm{O}$ apoio matricial tem demostrado ser uma ferramenta importante para aumentar 
a visibilidade e a legitimidade das demandas de sofrimento mental na rede de $\mathrm{AB}$ e uma estratégia potente para a qualificação da atenção à saúde mental ${ }^{52}$. Uma vez que no Brasil o modelo do apoio matricial está relacionado com uma política de apoio e qualificação de unidades com equipes de saúde da família e considerando que a amostra pesquisada conta com quase $70 \%$ de unidades com essas equipes, justifica-se o maior número de unidades da pesquisa realizarem reuniões de matriciamento (64,1\%). Embora não se tenha feito tal pergunta especificamente, nem todas as ações de matriciamento devem ser realizadas por Nasf, uma vez que o relato de cobertura de Nasf é menor do que o relato de ações de matriciamento (43,9\%).

Vale salientar que seria esperado, pelo que é proposto pela Política Nacional de Saúde Mental, que todas as unidades realizassem com certa frequência reuniões que indicassem solução de casos por meio de discussão interdisciplinar, intersetorial, considerando o território de vida das pessoas, e com a participação dos usuários. Dessa forma, nossos achados corroboram vários estudos que mostram que a $A B$ ainda tem uma frágil organização e um fraco planejamento para o cuidado em saúde mental nessa perspectiva ${ }^{17,27,29}$.

Em relação ao encaminhamento dos casos de saúde mental nos últimos três meses (tabela 3), observamos que os Caps são os principais locais de encaminhamentos realizados pela AB no estado de São Paulo (71,8\% das UBS). Em segundo lugar, estão os ambulatórios de saúde mental (32,7\%), que, embora postulados antes da Política de Saúde Mental estabelecida a partir de 2002 com a Portaria n ${ }^{0} 336^{7}$, subsistiram ao lado dos Caps. Esse dado pode indicar um maior conhecimento, legitimidade e uso dos serviços substitutivos criados a partir da Reforma Psiquiátrica em relação aos serviços anteriormente utilizados (hospitais psiquiátricos e ambulatórios de saúde mental). Vale notar que o Nasf foi relatado por $24,5 \%$ das unidades como local para onde foram encaminhados os casos de saúde mental, o que pode sugerir um uso equivocado dessas equipes de apoio, como se fossem um serviço substitutivo - talvez em razão da própria deficiência de serviços mais apropriados no território ou da falta de maior potência da $\mathrm{AB}$ no atendimento a casos menos graves.

No entanto, ainda foram encontradas $25,6 \%$ das unidades que encaminharam todos os seus casos de saúde mental, com variações segundo o tamanho do município; no município de São Paulo, apenas 9,8\% das unidades encaminhavam todos os seus casos (dados não apresentados em tabela). A saúde mental ainda é compreendida, em muitos contextos, como uma ação que deve ser respondida por especialistas da área; e, como relatado por outros estudos, alguns profissionais ainda encaram a ampliação da oferta de cuidados em saúde mental na $\mathrm{AB}$ como um acréscimo de trabalho (que extrapola suas funções e seus conhecimentos ou que gera sobrecarga) ou como falta de responsabilização da atenção especializada $27-29,52$. 
Tabela 4. Percentuais de respostas afirmativas às questões relativas às articulações com instituições/organizações/grupos externos à UBS, segundo o porte populacional dos municípios onde as unidades estão localizadas, e segundo a presença de profissional de saúde mental na unidade

\begin{tabular}{|c|c|c|c|c|c|c|c|c|c|c|c|c|}
\hline \multirow[t]{2}{*}{ Tema } & \multirow[t]{2}{*}{ Questão } & \multicolumn{4}{|c|}{ Porte populacional do município } & \multirow[t]{2}{*}{$\%$ total } & \multicolumn{2}{|c|}{$\mathrm{N}$ total valor de } & \multicolumn{2}{|c|}{ Profissional de SM } & \multicolumn{2}{|c|}{ total valor de } \\
\hline & & $\begin{array}{r}\text { Até } 25 \mathrm{mil} \\
\text { hab. }\end{array}$ & $\begin{array}{l}25 \text { a } 100 \\
\text { mil hab. }\end{array}$ & $\begin{array}{c}100 \mathrm{mil} \\
\text { hab. e + }\end{array}$ & $\begin{array}{r}\text { São } \\
\text { Paulo }\end{array}$ & & "sim" & $p^{\star}$ & Não & Sim & & $p^{*}$ \\
\hline \multirow{10}{*}{$\begin{array}{l}\text { Articulação } \\
\text { com grupos/ } \\
\text { instituições/ } \\
\text { organizações }\end{array}$} & $\mathrm{C} / \mathrm{Cras}$ & $95,4 \%$ & $91,8 \%$ & $97,6 \%$ & $93,4 \%$ & $95,1 \%$ & 525 & 0,087 & $94,2 \%$ & $96,2 \%$ & $95,1 \%$ & 0,287 \\
\hline & $\begin{array}{l}\text { C/Escola/ Creche/ } \\
\text { Universidade? }\end{array}$ & $76,4 \%$ & $57,6 \%$ & $80,7 \%$ & $90,7 \%$ & $75,5 \%$ & 412 & 0,000 & $70,8 \%$ & $80,3 \%$ & $75,3 \%$ & 0,010 \\
\hline & $\begin{array}{l}\text { C/ Equipamento da } \\
\text { Cultura }\end{array}$ & $12,6 \%$ & $7,8 \%$ & $18,2 \%$ & $34,2 \%$ & $16,6 \%$ & 89 & 0,000 & $12,1 \%$ & $21,5 \%$ & $16,5 \%$ & 0,003 \\
\hline & $\begin{array}{l}\text { C/ Equipamento de } \\
\text { Esporte }\end{array}$ & $26,0 \%$ & $13,8 \%$ & $27,1 \%$ & $28,8 \%$ & $23,9 \%$ & 129 & 0,021 & $19,3 \%$ & $28,9 \%$ & $23,8 \%$ & 0,009 \\
\hline & $\begin{array}{l}\text { C/ Assoc. de Bairro/ } \\
\text { Moradores }\end{array}$ & $7,9 \%$ & $14,7 \%$ & $37,0 \%$ & $52,0 \%$ & $26,9 \%$ & 145 & 0,000 & $24,3 \%$ & $29,7 \%$ & $26,9 \%$ & 0,158 \\
\hline & $\begin{array}{l}\text { C/ Grupos de Gera- } \\
\text { ção de Renda/ Coo- } \\
\text { perativas }\end{array}$ & $8,7 \%$ & $1,5 \%$ & $12,4 \%$ & $23,3 \%$ & $10,4 \%$ & 56 & 0,000 & $8,5 \%$ & $12,5 \%$ & $10,4 \%$ & 0,123 \\
\hline & $\begin{array}{l}\text { C/ Associação de } \\
\text { Idosos }\end{array}$ & $27,8 \%$ & $9,2 \%$ & $19,9 \%$ & $37,8 \%$ & $21,6 \%$ & 117 & 0,000 & $16,0 \%$ & $27,8 \%$ & $21,6 \%$ & 0,001 \\
\hline & $\begin{array}{l}\text { C/ Grupos de Ajuda } \\
\text { Mútua }\end{array}$ & $13,3 \%$ & $22,9 \%$ & $27,4 \%$ & $19,2 \%$ & $21,9 \%$ & 119 & 0,022 & $20,8 \%$ & $23,0 \%$ & $21,8 \%$ & 0,549 \\
\hline & C/Igrejas & $20,5 \%$ & $22,0 \%$ & $33,6 \%$ & $53,4 \%$ & $30,4 \%$ & 165 & 0,000 & $27,8 \%$ & $33,2 \%$ & $30,3 \%$ & 0,169 \\
\hline & $\begin{array}{l}\text { C/ Associações e } \\
\text { ONG }\end{array}$ & $41,4 \%$ & $34,9 \%$ & $42,9 \%$ & $59,5 \%$ & $42,9 \%$ & 233 & 0,008 & $37,4 \%$ & $48,8 \%$ & $42,8 \%$ & 0,007 \\
\hline
\end{tabular}

* valor de p para chi quadrado de Pearson.

Em relação ao uso de articulação intersetorial para o cuidado em saúde mental, (articulação com grupos, instituições e organizações), identificamos que a articulação com os Centros de Referência de Assistência Social (Cras) é a mais frequente $(91,5 \%$ das unidades - tabela 4), independentemente do porte populacional do município e da presença de profissional de saúde mental na unidade. Chama a atenção o fato de as unidades do município de São Paulo se destacarem apresentando os maiores percentuais de articulação intersetorial com diversas instituições fora da área da saúde para os cuidados em saúde mental. De modo geral, a proporção de unidades que responderam afirmativamente a essa questão é relativamente baixa (tabela 4). Esse dado pode indicar uma certa fragilidade e timidez na diversificação, sondagem e descoberta de outras instituições que poderiam compor a proposta de cuidado em saúde mental na ótica psicossocial, a partir das necessidades identificadas na vida dos usuários.

\section{Considerações finais}

Os resultados deste estudo reiteram, antes de tudo, o importante e oportuno papel da AB no rastreamento, na escuta, na identificação e no acolhimento da multiplicidade de manifestações do sofrimento mental vivido pela população, uma vez que, como demonstrado em muitos estudos, esses problemas são prevalentes, causam impedimentos e prejuízos variados à vida cotidiana e não são invisíveis nem infrequentes na Atenção Primária à Saúde. Assim, precisam de um olhar intencional e de uma propositada preocupação para que possam ser satisfatoriamente abordados. Nesse sentido, a análise dos dados aponta que existe ainda uma certa passividade e fragilidade na 
busca ativa de experiências humanas referentes à angústia, ao sofrimento emocional e psicossocial, sendo que a percepção desses problemas fica concentrada quando há pedidos explícitos de ajuda, sintomas mais graves ou quadros clínicos mais clássicos, já diagnosticados. Nessa mesma perspectiva, a troca de receitas, a compreensão mais biomédica e psiquiátrica desses problemas e a medicalização do cuidado em saúde mental ainda se mostram presentes nas unidades, o que dificulta uma abordagem mais extensamente psicossocial e territorial.

De forma geral, o planejamento e a gestão do cuidado em saúde mental nas unidades de $A B$ ainda são insatisfatórios, pois menos da metade das unidades possui um espaço interdisciplinar e multiprofissional regular para definir, discutir e reavaliar o cuidado. $\mathrm{O}$ apoio matricial se mostra uma estratégia significativa e promissora na organização das ações, já que foi a ferramenta mais utilizada pelas unidades para estruturar o cuidado. As articulações intersetoriais para o cuidado em saúde mental ainda se concentram especialmente nas organizações mais conhecidas de assistência social e em instituições de ensino. Embora esses vínculos sejam indiscutivelmente importantes para um trabalho mais integral, outras possibilidades e recursos do território são ainda muito pouco explorados.

A presença de profissionais de saúde mental nas unidades pesquisadas mostrou-se um elemento importante e diferencial na qualificação do cuidado e na abrangência das ações de natureza psicossocial. As unidades que contavam com esses profissionais reconheceram uma maior variedade de queixas e experiências como associadas a problemas de sofrimento mental (e não apenas sintomas psiquiátricos), utilizaram mais atividades de grupo para identificação dos problemas, estabeleceram mais articulações com equipamentos diversos do território e indicaram menor número de procedimentos de simples trocas de receitas. Tais elementos mostram o potencial da presença desses profissionais na $\mathrm{AB}$, ainda que apenas sua existência não garanta um cuidado de natureza psicossocial e mais abrangente.

As unidades do município de São Paulo se mostraram bastante potentes na identificação, na organização do cuidado, no manejo psicossocial dos problemas e na articulação com recursos da rede e do território, o que provavelmente se deve a estruturas mais robustas e complexas das unidades, tanto em espaço físico e em gestão como em recursos humanos. O investimento em saúde mental por parte de gestões anteriores da Prefeitura Municipal de São Paulo pode também ser um dos fatores que contribuíram para o desenvolvimento da área. Por sua vez, as unidades dos municípios menores (abaixo de 25 mil hab.) se destacaram também pela presença de profissionais de saúde mental e no uso de visitas de ACS para a identificação dos problemas, o que mostra a busca de alternativas próprias na ausência de equipamentos substitutivos e de uma rede estruturada.

Finalmente, vale a pena sublinhar a relevância da gestão municipal na formação permanente, no estabelecimento de espaços formalizados de interlocução entre as unidades da rede, no deliberado posicionamento diante de um trabalho territorializado e psicossocial, no apoio à articulação intersetorial no nível da macro e da micropolítica, no fortalecimento dos pontos de atenção da Raps, na gestão do processo de trabalho e no estabelecimento de diretrizes específicas para as linhas de cuidado em saúde mental53.

\section{Colaboradores}

Pupo LR (0000-0003-0925-152X)* contribuiu para a elaboração do artigo com as seguintes atividades: concepção, análise e interpretação dos dados; redação e revisão do conteúdo intelectual; responsabilidade pela garantia de exatidão e integridade do trabalho; aprovação final da versão a ser publicada. Rosa TEC (0000-0001-9285-0472)* contribuiu para concepção, análise e interpretação dos dados; para 
revisão crítica do conteúdo intelectual; para aprovação final da versão a ser publicada. Sala A (0000-0002-8941-8045)* contribuiu para concepção, análise e interpretação dos dados; para redação e revisão crítica do conteúdo intelectual. Feffermann M (0000-0001-80392152)* contribuiu para concepção, análise e interpretação dos dados; para revisão crítica do conteúdo intelectual; para aprovação final da versão a ser publicada. Alves MCGP (00000003-4357-9473)* contribuiu para concepção, análise e interpretação dos dados e para revisão crítica do conteúdo intelectual. Morais MLS (0000-0001-8791-2392)* contribuiu para concepção, análise e interpretação dos dados; para redação do artigo e revisão crítica do conteúdo intelectual; para aprovação final da versão a ser publicada.

\section{Referências}

1. Costa-Rosa A. O modo psicossocial: um paradigma das práticas substitutivas ao modo asilar. In: Amarante P, organizador. Ensaios: subjetividade, saúde mental, sociedade. Rio de Janeiro: Fiocruz; 2000. p. 141-168.

2. Gama CAP, Onocko Campos R. Saúde Mental na Atenção Básica - Uma pesquisa bibliográfica exploratória em periódicos de saúde coletiva (1997-2007). Cad. Brasil. Saúde Mental. 2009; 1(2):112-131.

3. Souza AC, Rivera FJU. A inclusão das ações de saúde mental na Atenção Básica: ampliando possibilidades no campo da saúde mental. Rev Tempus Actas Saúde Colet. 2010; 4(1):121-132.

4. Moline J, Lopes SMB. Saúde Mental na Atenção Básica: possibilidades para uma prática voltada para a ampliação e integralidade da saúde mental. Saúde Soc. 2013; 22(4):1072-1083.

5. Angelini CR, Caccia-Bava MCG. "A gente sente que precisa e pode...”: os desafios para a inclusão da saúde mental na Atenção Básica. Rev Bras Med Fam Comunidade. 2015; 10(36):1-9.
6. Brasil. Lei n ${ }^{\circ} 10.216$, de 06 de abril de 2001. Dispõe sobre a proteção e os direitos das pessoas portadoras de transtornos mentais e redireciona o modelo assistencial em saúde mental. Diário Oficial da União. 9 abr 2001. [acesso em 2020 set 20]. Disponível em: http://www.planalto.gov.br/ccivil_03/leis/leis_2001/ 110216.htm.

7. Ministério da Saúde. Portaria GM no 336, de 19 de fevereiro de 2002. Estabelece sobre modalidade as diferentes modalidades de Centros de Atenção Psicossocial (CAPS). Diário Oficial da União. 19 Fev 2002. [acesso em 2020 set 20]. Disponível em: https://bvsms.saude.gov.br/bvs/saudelegis/gm/2002/ prt0336_19_02_2002.html.

8. Brasil. Lei $n^{\circ} 10.708$, de 31 de julho de 2003. Institui o auxílio-reabilitação psicossocial para pacientes acometidos de transtornos mentais egressos de internações. Diário Oficial da União. 1 Ago 2003. [acesso em 2020 set 20]. Disponível em: http://www.planalto. gov.br/ccivil_03/Leis/2003/L10.708.htm.

9. Brasil. Ministério da Saúde. Portaria GM nº 2.197, de 14 de outubro de 2004. Redefine e amplia a atenção inte- 
gral para usuários de álcool e outras drogas, no âmbito do Sistema Único de Saúde - SUS, e dá outras providências. Diário Oficial da União. 14 Out 2004 [acesso em 2020 set 20]. Disponível em: http://bvsms.saude.gov. br/bvs/saudelegis/gm/2004/prt2197_14_10_2004. html\#: :text=Redefine $\% 20$ e\%20amplia\%20 a\%20aten\%C3\%A7\%C3\%A3o,SUS\%2C\%20e\%20 d\%C3\%A1\%20outras\%20provid\%C3\%AAncias.

10. Brasil. Ministério da Saúde. Portaria GM n 3.088, de 23 de dezembro de 2011. Institui a Rede de Atenção Psicossocial para pessoas com sofrimento ou transtorno mental e com necessidades decorrentes do uso de crack, álcool e outras drogas, no âmbito do Sistema Único de Saúde (SUS). Diário Oficial da União. 30 Dez 2011. [acesso em 2020 set 20]. Disponível em: http://bvsms.saude.gov.br/bvs/saudelegis/gm/2011/ prt3088_23_12_2011_rep.html.

11. Brasil. Ministério da Saúde, Secretaria de Atenção à Saúde. Saúde mental e atenção básica: o vínculo e o diálogo necessários. Brasília, DF: MS; 2007.

12. Brasil. Ministério da Saúde, Secretaria de Atenção à Saúde, Departamento de Atenção Básica. Sistema de informação da atenção básica: SIAB: indicadores 2005. Brasília, DF: Ministério da Saúde; 2005.

13. Brasil. Ministério da Saúde. Portaria GM n ${ }^{0}$ 1.097, de 22 de maio de 2006. Define o processo da Programação Pactuada e Integrada da Assistência em Saúde seja um processo instituído no âmbito do Sistema Único de Saúde. Diário Oficial da União. 23 Maio 2006. [acesso em 2020 set 20]. Disponível em: http://bvsms.saude.gov.br/bvs/saudelegis/gm/2006/prt1097_22_05_2006_comp. html\#: :text=1\%C2\%BA\%20Definir\%20que\%20a\%20 Programa\%C3\%A7\%C3\%A3o,bem\%20como\%20efetuados\%20os\%20pactos.

14. Brasil. Ministério da Saúde. Portaria GM no 154 , de 24 de janeiro de 2008. Cria os Núcleos de Apoio à Saúde da Família - NASF. Diário Oficial da União. 24 Jan 2008. [acesso em 2020 set 20]. Disponível em: https://bvsms.saude.gov.br/bvs/saudelegis/gm/2008/ prt0154_24_01_2008.html.
15. World Health Organization; World Organization of Family Doctors Working Party on Mental Health. What is primary care mental health? Ment. Health Fam. Med. 2008; 5(1):9-13.

16. World Health Organization; World Organization of Family Doctors. Integração da saúde mental nos cuidados de saúde primários: Uma perspectiva global. Lisboa: WHO/WONCA; 2009.

17. Aosani TR, Nunes KG. A saúde mental na atenção básica: a percepção dos profissionais de saúde. Rev. Psicol. Saúde. 2013; 5(2):71-80.

18. Wenceslau LD, Ortega F. Saúde mental na atenção primária e Saúde Mental Global: perspectivas internacionais e cenário brasileiro. Interface Botucatu. 2015; 19(55):1121-1132.

19. World Health Organization. Relatório Mundial da Saúde: Saúde mental: nova concepção, nova esperança. Lisboa: WHO, 2002.

20. Campos OR, Gama CAP. Saúde Mental na Atenção Básica. In: Campos GWS, Guerrero AVP, organizadores. Manual de Práticas da Atenção Básica. Saúde Ampliada e Compartilhada. 2. ed. São Paulo: Hucitec; 2010.

21. Brasil. Ministério da Saúde, Secretaria de Atenção à Saúde, Departamento de Atenção Básica; Departamento de Ações Programáticas Estratégicas. Cadernos de Atenção Básica. Brasília, DF: MS; 2013. (n. 34).

22. Yasui S, Costa-Rosa A. A estratégia Atenção Psicossocial: desafio na prática dos novos dispositivos de saúde mental. Saúde debate. 2008; 32(78/79/80): 27-37.

23. Brasil. Ministério da Saúde. Ministério da Saúde: Centro de Estudo e Pesquisa em Saúde Coletiva. Guia prático de matriciamento em saúde mental. Brasília, DF: MS; 2011.

24. Brasil. Ministério da Saúde. Secretaria de Atenção à Saúde, Departamento de Atenção Básica. Acolhimento à demanda espontânea Brasília, DF: Ministério da Saúde, 2011 
25. Moreira MIB, Onocko-Campos RT. Ações de saúde mental na rede de atenção psicossocial pela perspectiva dos usuários. Saúde Soc. 2017; 26(2):462-474.

26. Menezes ALA, Athie K, Favoreto CAO, et al. Narrativas de sofrimento emocional na Atenção Primária: contribuições para uma abordagem integral culturalmente sensível em Saúde Mental Global. Interface. Botucatu. 2019 [acesso em 2019 dez 20]; 23: el70803. Disponível em: http://www.scielo.br/scielo.php?script=sci arttext\&pid=S1414-32832019000100222\&lng=en\&n $\mathrm{rm}=$ iso.

27. Gerbaldo TZ, Arruda AT, Horta BL, et al. Avaliação da organização do cuidado em saúde mental na atenção básica à saúde do Brasil. Trab. Educ. Saúde. 2018; 16(3):1.079-1.094.

28. Sivinski T, Schenkel J. Pesquisa-Intervenção em Saúde Mental: Balançando as Redes da Saúde. Rev. Polis e Psique. 2018; 8(1):52-71.

29. Paulon S, Protazio M, Tschiedel R. "Eu sei o que é saúde mental!”: Pesquisar e Cuidar como Fios da Mesma Trama. Rev. Polis e Psique, 2018; 8(1):6-32.

30. Tanaka OY, Ribeiro EL. Ações de saúde mental na atenção básica: caminho para ampliação da integralidade da atenção. Ciênc. Saúde Colet. 2009; 14(2):477486.

31. Gryschek G, Pinto AAM. Saúde Mental: como as equipes de saúde da Família podem integrar esse cuidado na Atenção Básica? Ciênc. Saúde Colet. 2015; 20(10):3255-3262.

32. Shraiber LB, Mendes-Gonçalves RB. Necessidades de Saúde e Atenção Primária. In: Shraiber LB, Nemes MIB, Mendes-Gonçalves RB, organizadores. Saúde do Adulto: Programas e Ações na Unidade Básica. Saúde em Debate 96. São Paulo: Hucitec. 2000. p. 29-47. (Série Didática).

33. Cecílio LCO. As necessidades de saúde como conceito estruturante na luta pela integralidade e equidade na atenção. In: Pinheiro R, Mattos RA. Os sentidos da Integralidade na atenção e no cuidado à saúde. 8 . ed. Rio de Janeiro: CEPESC. IMS/UERJ/ABRASCO; 2006, p. 117-130.

34. Silva AP, Nascimento EGC, Pessoa Jr JM et al. "Por trás da máscara da loucura": cenários e desafios da assistência à pessoa com esquizofrenia no âmbito da Atenção Básica. Fractal, Rev. Psicol. 2019; 31(1):2-10.

35. Chaves SCS, Nobrega MPSS, Silva TS. Intervenções não farmacológicas ofertadas ao usuário com transtorno mental comum na atenção primária à saúde. J. nurs. health. 2019 [acesso em 2020 jan 15]; 9(3):e199302. Disponível em: https://periodicos.ufpel.edu.br/ojs2/ index.php/enfermagem/article/view/14472/10134.

36. Freitas F, Amarante PDC. Medicalização em Psiquiatria. 2. ed. Rio de Janeiro: Fiocruz; 2017.

37. Frances A. Voltando ao normal. Como o excesso de diagnósticos e a medicalização da vida estão acabando com a sanidade e o que pode ser feito para retomarmos o controle. Rio de Janeiro: Versal editores; 2017.

38. Zanella M, Luz HHV, Benetti IC, et al. Medicalização e saúde mental: Estratégias alternativas. Revista Portuguesa de Enfermagem de Saúde Mental. 2016; (15):53-62

39. Campos Junior A, Amarante PDC. Estudo sobre práticas de cuidado em saúde mental na Atenção Primária: o caso de um município do interior do estado do Rio de Janeiro. Cad. Saúde Colet. 2015; 23(4):425435 .

40. Brasil. Ministério da Saúde, Secretaria de Ciência, Tecnologia e Insumos Estratégicos. Síntese de evidências para políticas de saúde: Estratégias para a redução de prescrições inadequadas de antidepressivos no município de Franco da Rocha. Brasília, DF: Ministério da Saúde; 2019.

41. Campos, DB, Bezerra IC, Jorge MSB. Produção do cuidado em saúde mental: práticas territoriais na rede psicossocial. Trab. Educ. Saúde, Rio de Janeiro. 2020 [acesso em 2020 jan 20]; 18(1):e0023167. Disponível em: http://www.scielo.br/scielo.php?script=sci 
arttext\&pid=S1981-77462020000100502\&lng=pt\&nr $\mathrm{m}=\mathrm{iso}$.

42. Brasil. Ministério da Saúde, Secretaria de Atenção à Saúde, Departamento de Atenção Básica. Saúde da família no Brasil: uma análise de indicadores selecionados: 1998-2005/2006. Brasília, DF: Ministério da Saúde; 2008. (Série C. Projetos, Programas e Relatórios).

43. Brasil. Ministério da Saúde, Coordenação Geral de Alimentação e Nutrição (CGAN); Organização Pan-americana da Saúde (OPAS). Observatório de Políticas de Segurança Alimentar e Nutrição (OPSAN) Universidade de Brasília (UnB). Curso de auto aprendizado Redes de Atenção à Saúde no Sistema Único de Saúde. Brasília, DF: MS, 2012.

44. Martins AKL, Souza AMA, Vieira NFC, et al. Práticas em saúde mental na estratégia saúde da família: um estudo exploratório. Rev. Pesq. Cuid. Fundam. Online. 2015 [acesso em 2020 set 20]; 7(1):19051914. Disponível em: https://www.redalyc.org/ pdf/5057/505750945015.pdf.

45. Molina MRAL, Wiener CD, Branco JC, et al. Prevalência de depressão em usuários de unidades de atenção primária. Rev. psiquiatr. clín. 2012; 39(6):194-197.

46. Lucchese R, Sousa R, Bonfin SP, et al. Prevalência de transtorno mental comum na atenção primária. Acta paul. Enferm. 2014; 27(3):200-207.

47. Schneider DR, Lima DS. Implicações dos modelos de atenção à dependência de álcool e outras drogas na rede básica em saúde. Psico. 2011; 42(2):168-78.
48. Moura RFS, Castro e Silva CR. Saúde Mental na Atenção Básica: Sentidos Atribuídos pelos Agentes Comunitários de Saúde. Psicol., Ciênc. Prof. 2015; 35(1):199210.

49. Boccardo ACS, Zane FC, Rodrigues S, et al. O projeto terapêutico singular como estratégia de organização do cuidado nos serviços de saúde mental. Rev. Ter. Ocup. Univ. São Paulo, 2011; 22(1):85-92.

50. Grigolo TM, Garcia Jr CAS, Peres GM, et al. O Projeto Terapêutico Singular na clínica da atenção psicossocial. Cad. Brasil. Saúde Mental. 2015; 7(15):5373.

51. Vasconcelos MGF, Jorge MSB, Catrib AMF, et al. Projeto terapêutico em Saúde Mental: práticas e processos nas dimensões constituintes da atenção psicossocial. Interface. $2016 ; 20(57): 313-23$.

52. Amaral CEM, Torrenté MON, Torrenté M, et al. Apoio matricial em Saúde Mental na atenção básica: efeitos na compreensão e manejo por parte de agentes comunitários de saúde. Interface Botucatu. 2018; 22(66):801-12.

53. Heck R, Bielemann VR, Ceolin T, et al. A importância da gestão na Rede de Saúde Mental. Cien. Cuid. Saúde. 2008 [acesso em 2019 dez 2]; 7(supl2). Disponível em: http://periodicos.uem.br/ojs/index.php/ CiencCuidSaude/article/view/20961/pdf.

Recebido em 28/02/2020

Aprovado em 17/07/2020

Conflito de interesses: inexistente

Suporte financeiro: Projeto subsidiado pela Fundação de Amparo

à Pesquisa do Estado de São Paulo (Fapesp). Processo no

2016/15186-0 